\title{
3D numerical simulation of volcanic eruption clouds during the 2011 Shinmoe-dake eruptions
}

\author{
Yujiro J. Suzuki and Takehiro Koyaguchi \\ Earthquake Research Institute, University of Tokyo, 1-1-1 Yayoi, Bunkyo-ku, Tokyo 113-0032, Japan \\ (Received October 31, 2012; Revised March 15, 2013; Accepted March 16, 2013; Online published July 8, 2013)
}

\begin{abstract}
We present simulations of the development of volcanic plumes during the 2011 eruptions of the KirishimaShinmoe-dake volcano, Japan, using a new three-dimensional (3D) numerical model that calculates eruption cloud dynamics and the wind-borne transport of volcanic ash. This model quantitatively reproduces the relationship between the eruption conditions (e.g., magma discharge rate) and field observations, such as plume height and ash fall area. The simulation results indicate that the efficiency of turbulent mixing between ejected material and ambient air was substantially enhanced by strong winds during the 2011 Shinmoe-dake eruptions, which caused a significant decrease in the maximum height of the plumes compared with those that develop in still environment. Our 3D simulations also suggest that the existing 1D plume model tends to overestimate the effect of wind on turbulent mixing efficiency, and hence, to underestimate plume height in a strong wind field for a given magma discharge rate.
\end{abstract}

Key words: Volcanic plume, eruption column, numerical simulation, turbulent mixing.

\section{Introduction}

Explosive eruptions are characterized by the formation of buoyant plumes and widespread dispersal of volcanic ash. During such eruptions, a mixture of solid pyroclasts (volcanic ash) and volcanic gas is ejected from vents into the atmosphere. The ejected material (i.e., the mixture of solid pyroclasts and volcanic gas) generally has an initial density several times higher than that of the atmosphere, since it is composed of more than $90 \mathrm{wt} \%$ solid pyroclasts. As the ejected material entrains ambient air, expansion of this air during mixing with the hot pyroclasts drastically decreases the density of the mixture, so that it becomes less dense than the surrounding atmosphere. This results in the development of a buoyant volcanic plume with a height that can exceed several kilometers.

Volcanic plume height is one of the key observable quantities to estimate eruption conditions, including eruption intensity (i.e., magma discharge rate). Eruption column dynamics are controlled mainly by the balance between thermal energy ejected from the vent and the work done during transportation of ejected material and entrained air through atmospheric stratification. This means that when magma properties (i.e., temperature, volatile content, and heat capacity) are fixed, plume height is dependent on the efficiency of turbulent mixing, the magma discharge rate and atmospheric conditions (Morton et al., 1956; Sparks, 1986; Carazzo et al., 2008); at given atmospheric conditions (e.g., temperature and moisture stratifications) the plume height increases as magma discharge rates increase and turbulent

Copyright (c) The Society of Geomagnetism and Earth, Planetary and Space Sciences (SGEPSS); The Seismological Society of Japan; The Volcanological Society of Japan; The Geodetic Society of Japan; The Japanese Society for Planetary Sciences; TERRAPUB.

doi:10.5047/eps.2013.03.009 mixing efficiencies decrease.

The flow patterns of a volcanic plume are also strongly dependent on whether plume vertical velocities are faster or slower than wind speeds (Bonadonna et al., 2005). Plume trajectories are not wind-affected at high eruption intensities and/or under weaker wind speeds. The vertically rising plume spreads horizontally at the level where cloud density is equal to that of the atmosphere, termed the neutral buoyancy level (NBL; Sparks, 1986). In comparison, if eruption intensity is weak and/or wind speeds are high, volcanic plumes are highly wind-distorted, leading to a bent-over trajectory, and the deposition of volcanic ash at significant distances from the vent. Recently, Bursik (2001) proposed a theoretical model of bent-over plume, and suggested that wind enhances the efficiency of turbulent mixing, leading to a decrease in plume height. However, the effects of wind on turbulent mixing efficiency and plume height are not fully understood.

In the first stage of the 2011 Kirishima-Shinmoe-dake volcano eruptions in Japan, three volcanic plumes were strongly affected and distorted by a westerly wind with volcanic ash transported toward the southeast. Weather radar echo measurements indicated that these plumes reached heights of up to $6.5-8.5 \mathrm{~km}$ above sea level (asl; Shimbori and Fukui, 2012). Kozono et al. (2013) demonstrated that these plume heights were significantly lower than those predicted by a simple plume height model. This implies that environmental winds enhance turbulent mixing and cause a decrease in plume height, as was suggested by Bursik (2001). Here, we present a new 3D numerical model of bent-over plumes and attempt to reproduce the plume height and ash fall area for the 2011 Shinmoe-dake eruptions. We discuss the effects of wind on the efficiency of turbulent mixing and the plume height. 


\section{Numerical Model}

Our numerical model is designed to simulate the injection of a mixture of solid pyroclasts and volcanic gas from a circular vent above a flat earth surface in a stratified atmosphere, using a combination of a pseudo-gas model for fluid motion and a Lagrangian model for particle motion. We ignore the separation of solid pyroclasts from the eruption cloud during fluid dynamics calculations, treating an eruption cloud as a single gas with a density calculated using a mixing ratio between ejected material and entrained air. The fluid dynamics model solves a set of partial differential equations that describe the conservation of mass, momentum, and energy, and constitutive equations describing the thermodynamic state of the mixture of pyroclasts, volcanic gas, and air. These equations are solved numerically by a general scheme for compressible flow (van Leer, 1977; Roe, 1981). Details of the numerical procedures used in this study are described in Suzuki et al. (2005).

Our model employs Lagrangian marker particles of various sizes in some runs to calculate ash particle transport, with particles modeled as ideal spheres. The density of particles is assumed to be $1000 \mathrm{~kg} \mathrm{~m}^{-3}$, and 200 marker particles are ejected from the vent every $10 \mathrm{sec}$ at the same velocity as the pseudo-gas. Particle grain sizes are randomly selected within a range of 0.0625 to $64 \mathrm{~mm}$ (i.e., $4 \phi$ to $-6 \phi)$, with a terminal velocity for individual particles $\left(V_{\mathrm{t}}\right)$ determined for three ranges of particle Reynolds numbers $(\mathrm{Re})$, as follows:

$$
\begin{aligned}
& V_{\mathrm{t}}=\left(\frac{3.1 g \sigma d}{\rho_{\mathrm{a}}}\right)^{1 / 2} \quad(\operatorname{Re}>500) \\
& V_{\mathrm{t}}=d\left(\frac{4 g^{2} \sigma^{2}}{225 \mu \rho_{\mathrm{a}}}\right)^{1 / 3}(6<\mathrm{Re}<500) \\
& V_{\mathrm{t}}=\frac{g \sigma d^{2}}{18 \mu} \quad(\operatorname{Re}<6)
\end{aligned}
$$

where $g$ is the gravitational body force per unit mass, $\sigma$ is the particle density, $d$ is the particle diameter, $\rho_{\mathrm{a}}$ is atmospheric density, and $\mu$ is the dynamic viscosity of air (e.g., Kunii and Levenspiel, 1969). Particle Reynolds numbers are defined as:

$$
\operatorname{Re}=\frac{\sigma d \Delta v}{\mu},
$$

where $\Delta v$ is the vertical component of relative velocity between the particle and ambient fluid (i.e., mixture of ejected pseudo-gas and air). This velocity $\left(V_{\mathrm{t}}\right)$ is added to the vertical velocity of fluid motion at every time step, until the marker particle ceases its motion and settles as sediment when they reach the ground surface.

Calculations were performed in a 3D domain with a nonuniform grid; a computational domain extends $13 \mathrm{~km}$ vertically ( $Z$-direction) and $24 \times 12 \mathrm{~km}$ horizontally $(X$ - and $Y$-directions, respectively). The boundaries are located 2 $\mathrm{km}$ north, $10 \mathrm{~km}$ south, $1 \mathrm{~km}$ west, and $23 \mathrm{~km}$ east from the volcanic vent center, which is at $1400 \mathrm{~m}$ asl. A free-slip condition is applied at the ground boundary for ejected material and air velocities, with mass, momentum, and energy fluxes at the upper and other boundaries of the computational domain assumed to be continuous; these boundary conditions correspond to free outflow and inflow for these quantities.
Entrainment of ambient air by turbulent mixing plays a central role in the dynamics of eruption clouds, primarily because the cloud density is controlled by the mixing ratio between ejected material and ambient air. Generally speaking, the efficiency of entrainment is a function of the Reynolds number. However, it is independent of the Reynolds number when the turbulence is fully developed (Dimotakis, 2000). Because the flow of volcanic plume is considered to be fully turbulent, to correctly reproduce the entrainment efficiency in the plume, our simulations must use a sufficiently high spatial resolution (Suzuki et al., 2005). This means that during simulation, grid sizes were set to be smaller than $D_{0} / 16$ near the vent, where $D_{0}$ is the vent diameter, and to increase at a constant rate (by a factor of 1.02) with distance from the vent up to $D_{0} / 2$, such that the grid size is small enough to resolve turbulent flow at locations far from the vent (cf. Suzuki and Koyaguchi, 2010).

\section{Simulation Input Parameters}

Shinmoe-dake volcano, located in Kyushu, Japan, produced a sustained explosive eruption between January 26 and 27 of 2011. Three major sub-Plinian eruptions were detected using weather radar echo measurements (Shimbori and Fukui, 2012) from 16:10 to 18:40 JST (Japan Standard Time, UT + 09:00) on January 26, and from 2:00 to 5:00, and 16:20 to 18:00 JST, on January 27; see Kozono et al. (2013) for a more detailed description of these 2011 eruptions. Here, we attempt to simulate the volcanic plume in this sub-Plinian phase of eruption, using the input parameters and material properties listed in Table 1.

The atmospheric conditions during January 26 to 27 were calculated using the Japan Meteorological Agency's NonHydrostatic Model (JMANHM; Hashimoto et al., 2012). This model provides vertical atmospheric density, pressure, temperature, and wind velocity profiles (Fig. 1), indicating that temperature decreased linearly with height (Fig. 1(b)), with northwesterly winds dominating near the vent (Fig. 1(c) and 1(d)). The speed of this westerly wind increased with height, reaching $80 \mathrm{~m} \mathrm{~s}^{-1}$ at $11 \mathrm{~km}$ asl. (Fig. 1(c)). In the simulations presented here, initial at-

Table 1. Material properties, physical parameters, and input parameters for simulation.

\begin{tabular}{ll} 
Parameter & Value \\
\hline Gravitational body force per unit mass, $g$ & $9.81 \mathrm{~m} \mathrm{~s}^{-2}$ \\
Density of solid pyroclasts, $\sigma$ & $1000 \mathrm{~kg} \mathrm{~m}^{-3}$ \\
Specific heat of solid pyroclasts, $C_{\mathrm{vs}}$ & $1100 \mathrm{~J} \mathrm{~kg}^{-1} \mathrm{~K}^{-1}$ \\
Specific heat of volcanic gas, $C_{\mathrm{vg}}$ & $1348 \mathrm{~J} \mathrm{~kg}^{-1} \mathrm{~K}^{-1}$ \\
Specific heat of air, $C_{\mathrm{va}}$ & $713 \mathrm{~J} \mathrm{~kg}^{-1} \mathrm{~K}^{-1}$ \\
Gas constant of volcanic gas, $R_{\mathrm{g}}$ & $462 \mathrm{~J} \mathrm{~kg}^{-1} \mathrm{~K}^{-1}$ \\
Gas constant of air, $R_{\mathrm{a}}$ & $287 \mathrm{~J} \mathrm{~kg}^{-1} \mathrm{~K}^{-1}$ \\
Altitude of vent & $1400 \mathrm{~m}$ \\
Volatile content, $n_{\mathrm{g} 0}$ & $3 \mathrm{wt} \%$ \\
Magma temperature, $T_{0}$ & $1273.15 \mathrm{~K}^{-3}$ \\
Initial mixture density, $\rho_{0}$ & $5.74 \mathrm{~kg} \mathrm{~m}^{-3}$ \\
Mass discharge rate, $\dot{m}_{0}$ & $1.5 \times 10^{6} \mathrm{~kg} \mathrm{~s}^{-1}$ \\
Exit velocity, $w_{0}$ & $134 \mathrm{~m} \mathrm{~s}^{-1}$ \\
Vent diameter, $D_{0}$ & $49 \mathrm{~m}$ \\
\hline
\end{tabular}


(a)

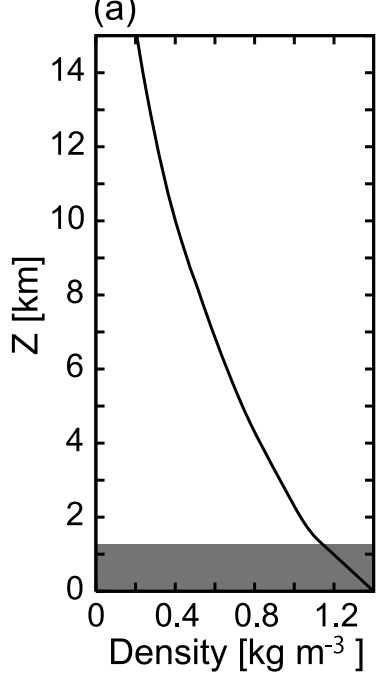

(b)

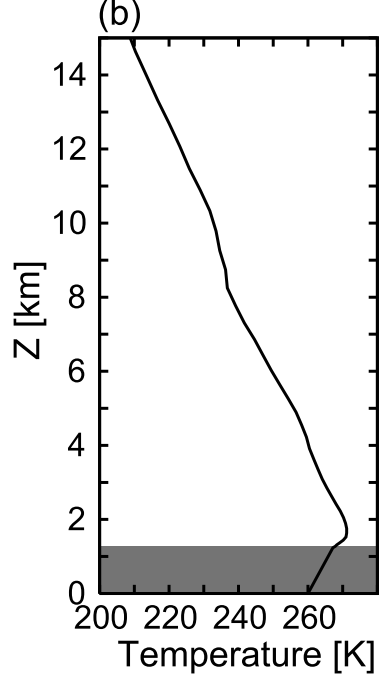

(c)

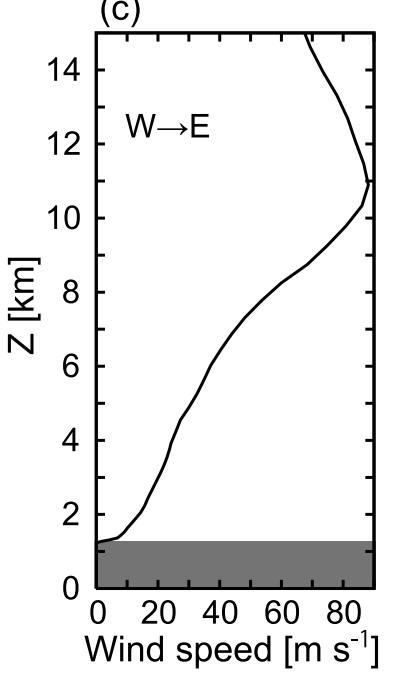

(d)

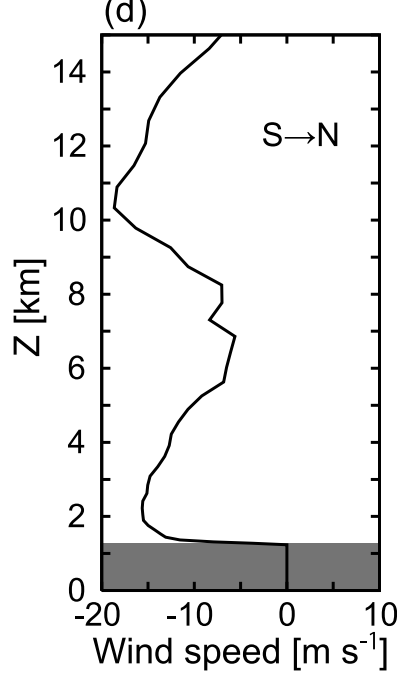

Fig. 1. Initial atmospheric conditions used during simulations: (a) density, (b) temperature, (c) wind speed from west to east, (d) wind speed from south to north; profiles were provided by the Japan Meteorological Agency's Non-Hydrostatic Model (Hashimoto et al., 2012).

mospheric conditions are given as a function of height $(Z)$ using these vertical profiles, and are assumed to be horizontally uniform at each height, with vertical wind velocity assumed to be zero.

Magmatic properties (i.e., volatile content and magma temperature) were estimated from petrological data, with Suzuki et al. (2013) documenting that volatile contents $\left(\mathrm{H}_{2} \mathrm{O}\right)$ ranges from 3 to $5 \mathrm{wt} \%$ with magma temperatures around $1273 \mathrm{~K}$. On the basis of these data, the volatile content $n_{\mathrm{g} 0}$ and magma temperature $T_{0}$ in the simulations presented here are set to be $3 \mathrm{wt} \%$ and $1273 \mathrm{~K}$, respectively.

Magma discharge rates were precisely estimated using a combined geodetic and satellite observation-based method (Kozono et al., 2013). A combination of geodetic volume change and lava effusion volume enabled an estimation of the magma discharge rate during the sub-Plinian events, at $450-741 \mathrm{~m}^{3} \mathrm{~s}^{-1}$, corresponding to $1.13-1.85 \times 10^{6} \mathrm{~kg} \mathrm{~s}^{-1}$. These results are consistent with an estimate based on the total amount of tephra fall deposits divided by the eruption duration (Maeno et al., 2012). Here, we assume that the magma discharge rate was $1.5 \times 10^{6} \mathrm{~kg} \mathrm{~s}^{-1}$.

In general, the pressure of a gas-pyroclast mixture deviates from atmospheric pressure during explosive eruptions, with the mixture accelerated and/or decelerated during decompression and/or compression immediately above the vent (Woods and Bower, 1995; Ogden et al., 2008; Koyaguchi et al., 2010). For simplicity, we assume that the pressure at the vent is equal to atmospheric pressure, as the pressure of the mixture is considered to approach atmospheric values at a short distance from the vent (5-20 vent radii). This assumption means that the initial density of the ejected material $\rho_{0}$ is given as a function of $T_{0}$ and $n_{\mathrm{g} 0}$, with the exit velocity $w_{0}$ tentatively assumed to be the sound velocity of the mixture $\left(134 \mathrm{~m} \mathrm{~s}^{-1}\right)$. When the magma discharge rate $\dot{m}_{0}$, mixture density $\rho_{0}$, and exit velocity $w_{0}$ are given, the vent diameter $D_{0}$ is calculated from the relationship as:

$$
\dot{m}_{0}=\pi \rho_{0} w_{0}\left(D_{0} / 2\right)^{2} .
$$

\section{Simulation Results}

Our simulation successfully reproduced a wind-distorted volcanic plume (Fig. 2), with the volcanic plume blown to the southeast by low-altitude winds immediately after the eruption (Fig. 2(a) and 2(e)). The plume continues to rise vertically and move horizontally parallel to the wind direction (Fig. 2(b) and 2(f)). The head of the plume subsequently stops rising and bends toward the east-southeast by high-altitude west-northwesterly winds (Fig. 2(c) and 2(g)). At $480 \mathrm{sec}$, a distal horizontally moving cloud develops at $6-8 \mathrm{~km}$ asl $(L>6 \mathrm{~km}$, where $L$ is horizontal distance from the vent), whereas a bent-over plume develops proximal to the vent $(L<6 \mathrm{~km}$; Fig. 2(d) and 2(h)).

Figure 3 illustrates the cross-sectional distribution of physical quantities at $480 \mathrm{~s}$, with a gas-pyroclast mixture ejected from the vent with a higher density $\left(5.74 \mathrm{~kg} \mathrm{~m}^{-3}\right)$ and a higher temperature $(1273 \mathrm{~K})$ than the density $(1.11 \mathrm{~kg}$ $\left.\mathrm{m}^{-3}\right)$ and temperature $(270 \mathrm{~K})$ of the atmosphere at ground level (1400 $\mathrm{m}$ asl). As the cloud rises, it entrains ambient air to decrease the mixture density and to increase cloud buoyancy (Fig. 3(a)). Temperatures in the rising plume remain higher than the atmospheric temperature (Fig. 3(b)). When the cloud moves horizontally at a height of $6-8 \mathrm{~km}$, the mass fraction of the ejected material decreases to $<0.05$ because of air entrainment (Fig. 2(h)). In this horizontally moving cloud, the density and temperature of the cloud become almost equal to those of the atmosphere at the same level.

The simulations presented here also reproduce particle separation and sedimentation from the volcanic plume (Fig. 4). The marker particles ejected from the vent at the same velocity as the pseudo-gas (i.e., $134 \mathrm{~m} \mathrm{~s}^{-1}$ ) are carried upward by turbulent flow, then leave from the cloud because their density is higher than that of the gas phases. Fine particles (shown as red points in Fig. 4(a)) are transported to the top of the plume, drift toward the east-southeast in the horizontally moving cloud, and spread toward wind direction gradually in distance (Fig. 4(b) and 4(c)). In comparison, coarse particles (blue points) leave from the volcanic plume 

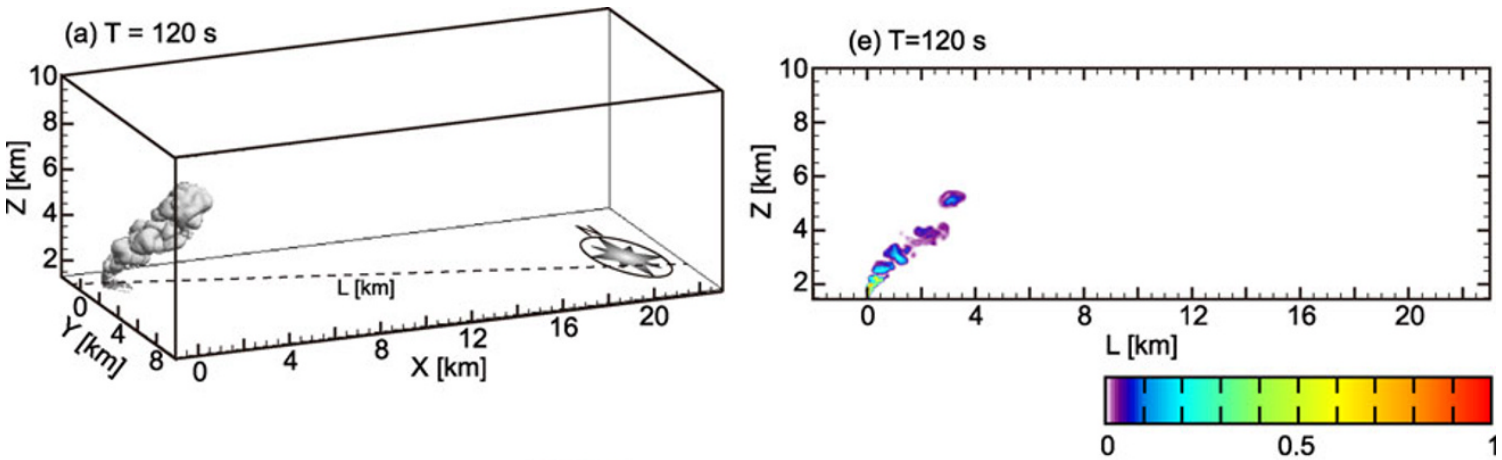

(b) $\mathrm{T}=240 \mathrm{~s}$

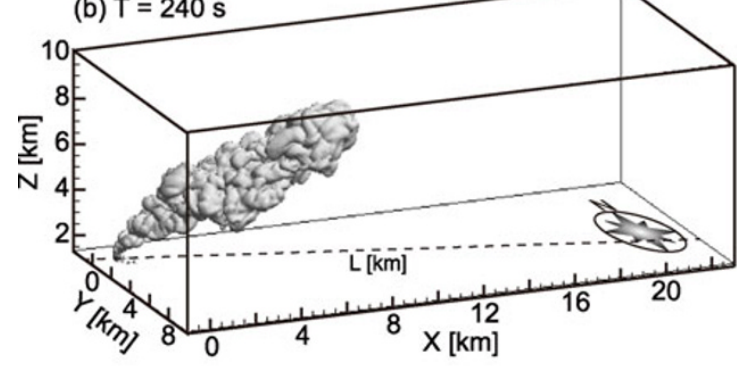

(c) $\mathrm{T}=360 \mathrm{~s}$

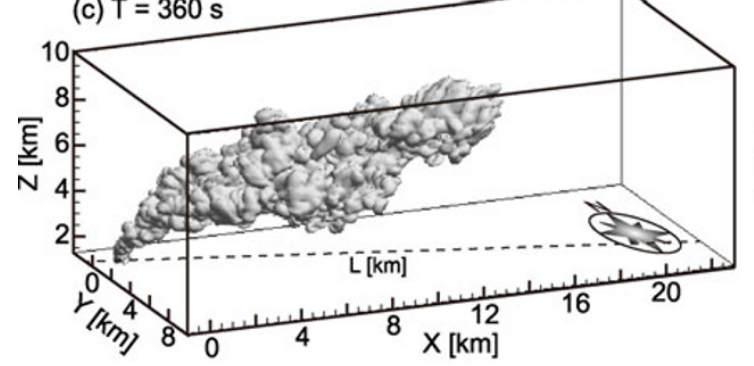

(d) $\mathrm{T}=480 \mathrm{~s}$

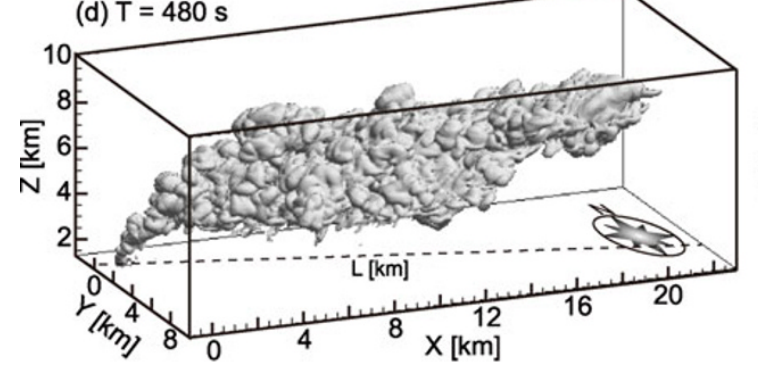

(f) $\mathrm{T}=240 \mathrm{~s}$

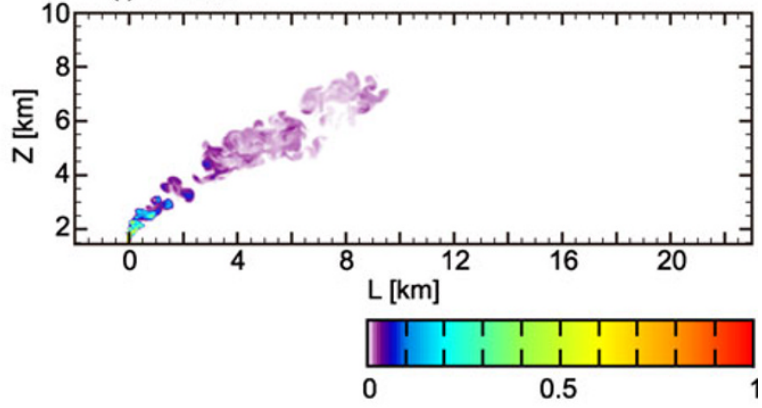

(g) $\mathrm{T}=360 \mathrm{~s}$

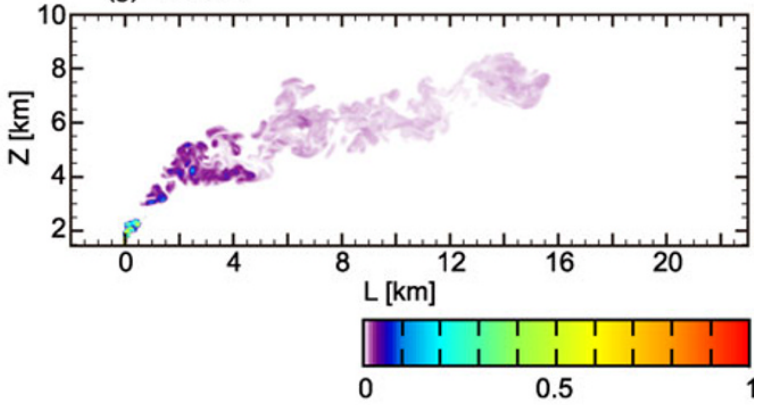

(h) $\mathrm{T}=480 \mathrm{~s}$

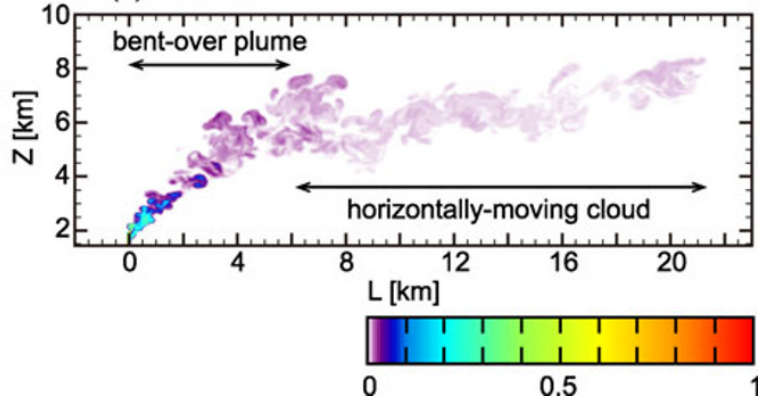

Fig. 2. Results of 3D numerical model of the development of a bent-over plume during the 2011 Shinmoe-dake eruptions; (a-d) isosurface of $\xi=0.01$ at $120,240,360$, and $480 \mathrm{~s}$ from eruption initiation, respectively, where $\xi$ is the mass fraction of the ejected material; (e-f) cross-sectional distribution of $\xi$; positions of cross-sections are indicated by dotted lines in (a-d). Parameters used and vent conditions are given in Table 1.

and fall to the ground near the vent. Medium-sized particles (yellow and green points) are transitional between the fine and coarse particles, and go to higher level than the coarse particles, but not to the top of the plume (Fig. 4(a) and 4(c)). Their segregations take place both from the plume and the horizontally moving cloud.

These results suggest that the distribution of fall deposits is controlled not only by the wind direction at the level of the horizontally moving cloud, but also by wind directions at low altitudes. The fact that the northwesterly wind predominates at low altitudes (Fig. 1(c) and 1(d)) means that the particles left from the cloud drift toward the southeast (Fig. 4(c)), causing the dispersal axis of the main fall deposit to extend toward the southeast, whereas the main horizontally moving cloud axis extends east-southeasterly (Fig. 5). Such shift of the dispersal axis relative to the position of the horizontally moving cloud was also observed with the airfall deposit of the Mount St. Helens 1980 eruption (Sarna-Wojcicki et al., 1981). Figure 5(b) also indicates that the axis directions are dependent on the grain size. The fine particles leave from the top of the plume with low terminal velocities, whereas the coarse particles 

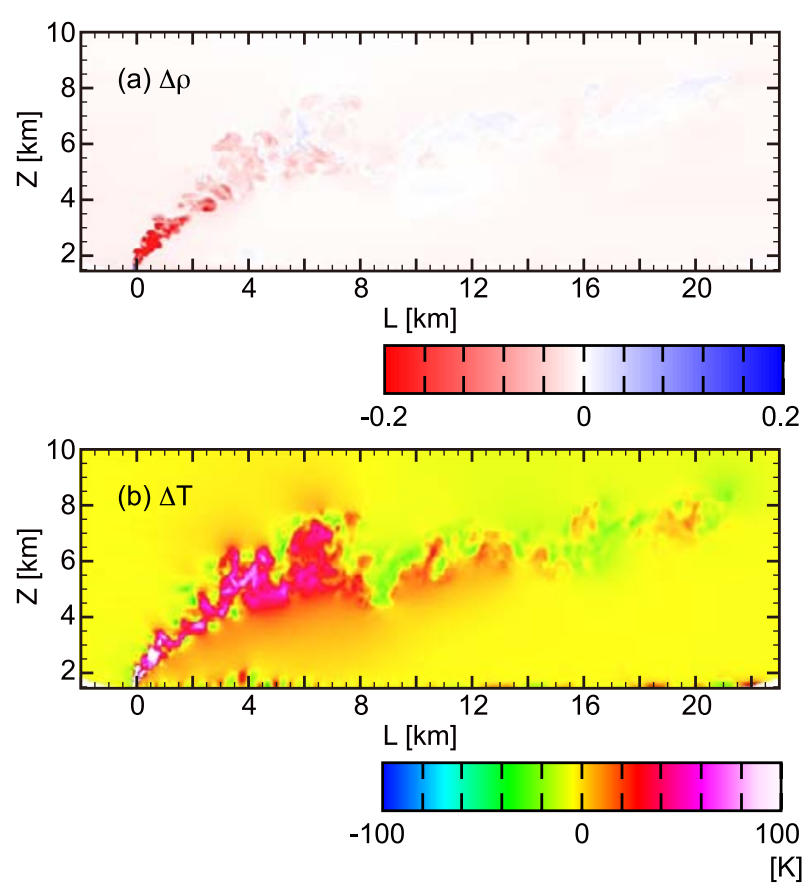

Fig. 3. Cross-sectional distributions of (a) density difference relative to stratified atmospheric density at the same height, $\Delta \rho=\rho / \rho_{\mathrm{a}}-1$, and (b) the temperature difference, $\Delta T=T-T_{\mathrm{a}}$, at $480 \mathrm{~s}$ from eruption initiation, where $\rho_{\mathrm{a}}$ and $T_{\mathrm{a}}$ are atmospheric density and temperature, respectively. Positions of cross-sections are indicated by dotted lines in Fig. 2(d). Parameters used and vent conditions are given in Table 1.

leave from the plume at low altitudes with high terminal velocities. Because of their low terminal velocities, the trajectories of fine particles are shifted southward by the lowaltitude wind more strongly than those of coarse particles. As a result, the dispersal axis of fine particles extends to the southeast (red and orange points in Fig. 5(b)), whereas that of coarse particles extends to the east-southeast (blue points).

The simulated plume height and shape are quantitatively consistent with the weather radar echo observation at heights of $6.5-8.5 \mathrm{~km}$ (Shimbori and Fukui, 2012). The result illustrated in Fig. 5(a) also agrees with visible and infrared satellite images sequentially captured by JMA that show clouds drifting toward the east-southeast. In addition, Fig. 5(b) indicates that the dispersal axis of the main fall deposit within our simulations is consistent with field observations (Maeno et al., 2012). As mentioned above, our model predicts some interesting features of the fall deposits, with the size of particles deposited on the ground decreasing with increasing horizontal distance from the vent, and the orientation of the main axis potentially being grain size dependent (see colors in Fig. 5(b)). More detailed and quantitative comparisons between simulation results (using a much larger number of marker particles) and field observations are needed to provide more realistic depositional patterns.

\section{Discussion}

Our simulations successfully reproduce the basic features of syn- and post-eruptive field observations, such as the height and shape of the plume, the direction of the horizontally moving cloud, and the dispersal axis of the main fall deposit. In particular, the plume height in our 3D model quantitatively agrees with observed plume heights (6.5-8.5 $\mathrm{km}$ ); this is important, as plume height is one of the key observable quantities used in estimating magma discharge rates (e.g., Suzuki and Koyaguchi, 2009). Magma discharge rates during explosive eruptions in a still environment have been estimated using steady one-dimensional (1D) volcanic plume models (e.g., Woods, 1988; Carrazo et al., 2008). Here, we present a detailed comparison between our 3D results and predictions using a steady $1 \mathrm{D}$ model, and discuss how the relationship between magma discharge rate and plume height changes when wind effects are taken into account.

Steady 1D models are based on the entrainment hypothesis, where the mean inflow velocity across the edge of a turbulent flow (jet and/or plume) $U_{\mathrm{e}}$ is proportional to the mean vertical velocity $U$ (Morton et al., 1956):

$$
U_{\mathrm{e}}=k U
$$

The proportionality constant $k$ represents the efficiency of turbulent mixing and is termed "the entrainment coefficient", with experimental studies suggesting that $k$ values are about 0.1 for a turbulent jet and/or plume ejected from a nozzle into a uniform or linearly stratified environment (e.g., Morton et al., 1956; Wang and Law, 2002). Woods (1988) developed a model for volcanic plumes using this hypothesis; the model quantitatively reproduced observed plume heights in a still environment, referred to here as "the 1D no-wind model". This 1D model is supported by the results of recent 3D simulations in a still environment (Suzuki et al., 2005; Suzuki and Koyaguchi, 2009).

Unlike in still environments, the height of bent-over plumes in a strong wind field can deviate from predictions of the 1D no-wind model (Fig. 6), with the observed height of the bent-over plume during the 2011 Shinmoe-dake eruptions, as well as the results of our 3D simulation, being significantly lower than those predicted by a $1 \mathrm{D}$ no-wind model and a $k$ value of 0.1 . Plume heights based on a 1D no-wind model using variable values of $k$ are also shown in Fig. 6 as a function of magma discharge rate. When magma discharge rate is fixed, the plume height increases as assumed entrainment coefficient decreases. This is because plume height is determined mainly by the balance between the thermal energy ejected at the vent and the work done in transporting ejected material plus entrained air through atmospheric stratifications; see Woods (1988) for a detailed discussion. Both the height of the bent-over plume in the 3D simulations presented here and the observed height of the plume are consistent with $1 \mathrm{D}$ no-wind model estimates using $k$ values of $0.16-0.20$.

The results shown in Fig. 6 indicate an enhanced efficiency of turbulent mixing that is caused by a wind-derived increase in entrainment coefficient values. Bursik (2001) proposed a modified 1D volcanic plume model where the effects of wind on turbulent mixing efficiency are taken into account; this model is referred to as "the 1D wind model". In this model, entrainment velocities are represented as

$$
U_{\mathrm{e}}=k\left|U-U_{\mathrm{w}} \cos \theta\right|+\beta\left|U_{\mathrm{w}} \sin \theta\right|,
$$



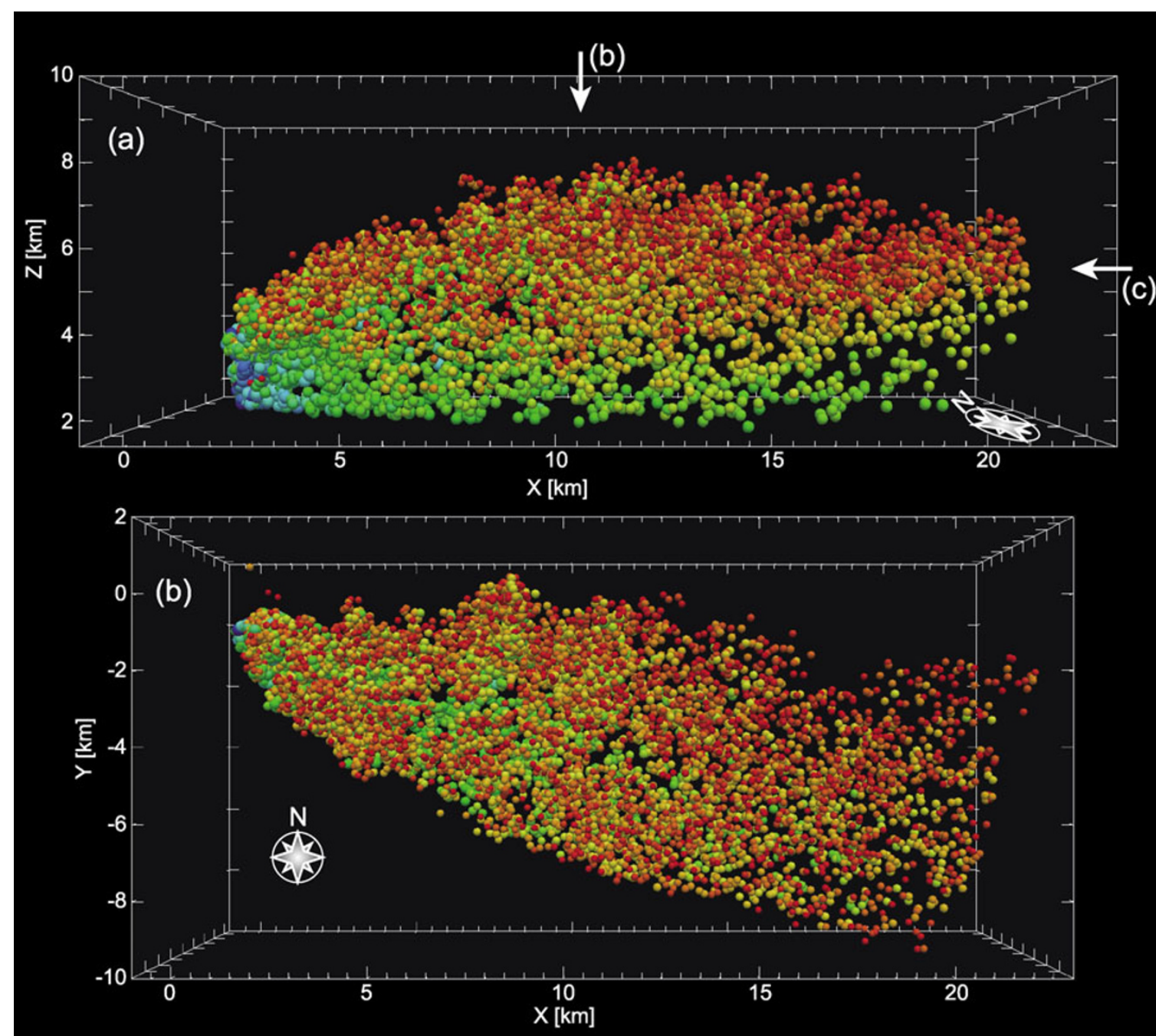

(c)

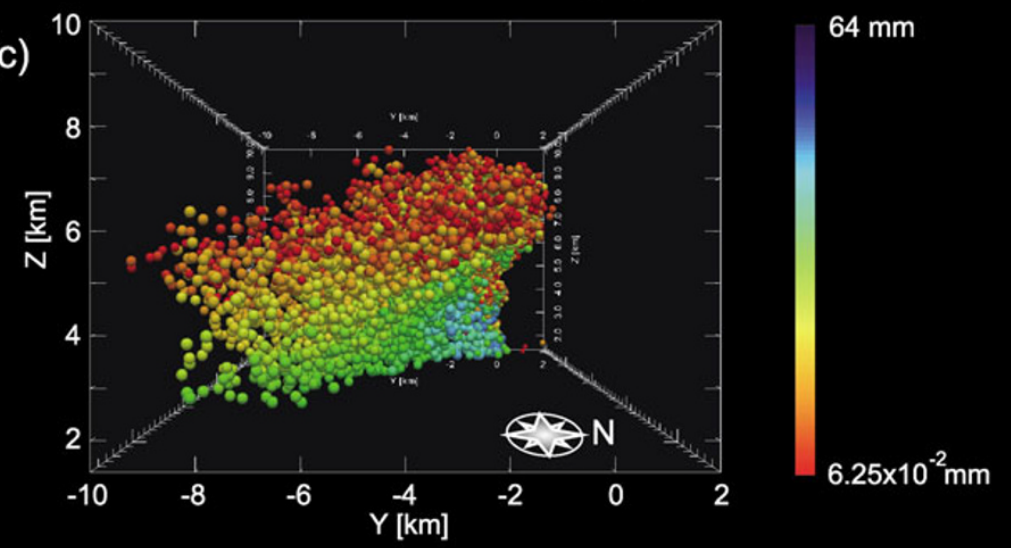

Fig. 4. 3D distributions of marker particles at $600 \mathrm{~s}$ from the eruption initiation, with (a) side view from the south, (b) top view, and (c) side view from the east shown; the viewing directions in (b) and (c) are indicated by arrows in (a). Particle colors represent particle sizes, ranging from $0.0625 \mathrm{~mm}$ $(4 \phi)$ to $64 \mathrm{~mm}(-6 \phi)$. Parameters used and vent conditions are given in Table 1.

where $U_{\mathrm{w}}$ is the wind velocity, $\theta$ is a coordinate expressing the inclination of the plume centerline with respect to the horizon, and $\beta$ is an entrainment coefficient related to wind-caused entrainment. The first term on the right-hand side of the equation is entrainment by radial inflow minus the amount swept tangentially by the wind along the plume margin, with the second term being wind entrainment. When $\beta=0.7$ (Hewett et al., 1971) and $k=0.1$, the $1 \mathrm{D}$ wind model predicts a plume height of $4.6 \mathrm{~km}$ for a magma discharge rate of $1.5 \times 10^{6} \mathrm{~kg} \mathrm{~s}^{-1}$, significantly lower than the observed plume height. This indicates that the $1 \mathrm{D}$ wind model overestimates the effects of wind on turbulent mixing efficiency.

The fact that plume heights estimated using the 3D model presented here are quantitatively consistent with observations indicates that our model accurately reproduces turbulent mixing in volcanic plumes. These 3D numerical simulations are a powerful tool that allows the investigation 

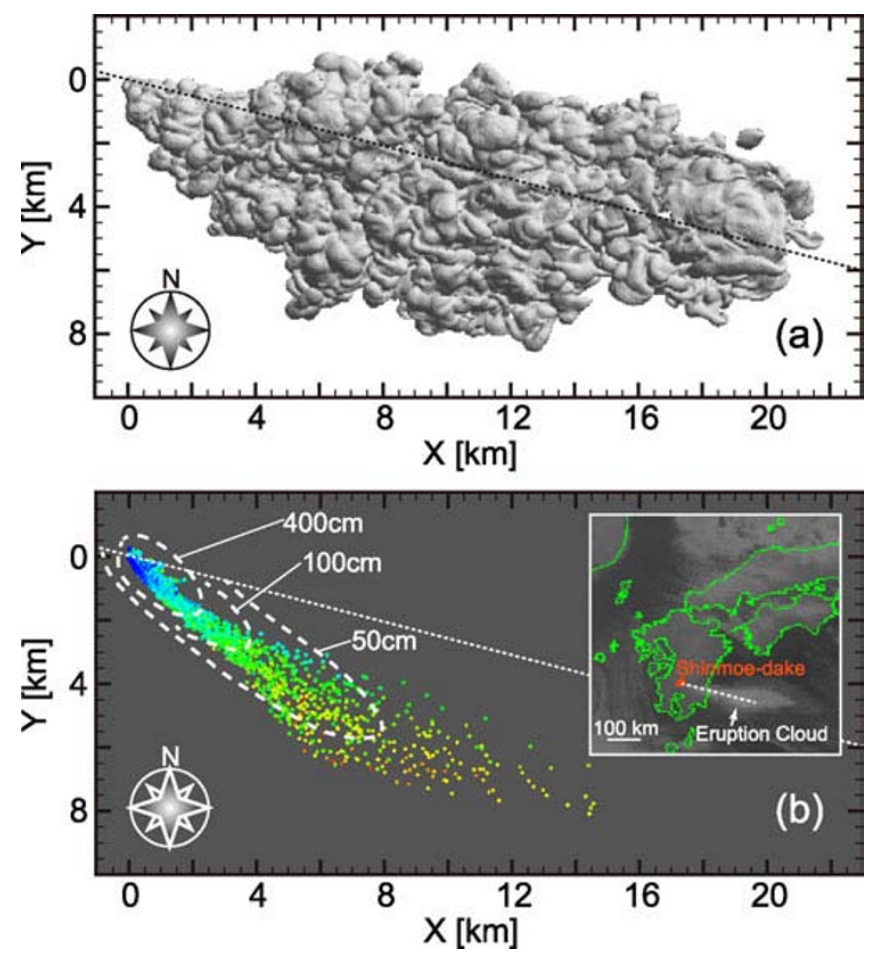

Fig. 5. (a) Top view of the isosurface of $\xi=0.01$ at $480 \mathrm{~s}$ and (b) depositional pattern of marker particles at ground level; dashed curves in (b) represent isomass lines from the 26-27 January 2011 sub-Plinian eruptions of the Shinmoe-dake volcano, as observed in the field (Maeno et al., 2012). Parameters used and vent conditions are given in Table 1. Inset in (b) is the infrared image taken by MTSAT-2 at 18:00 JST on January 26. The dotted lines in (a) and (b) represent the axis direction of the horizontally moving cloud observed by the satellite image.

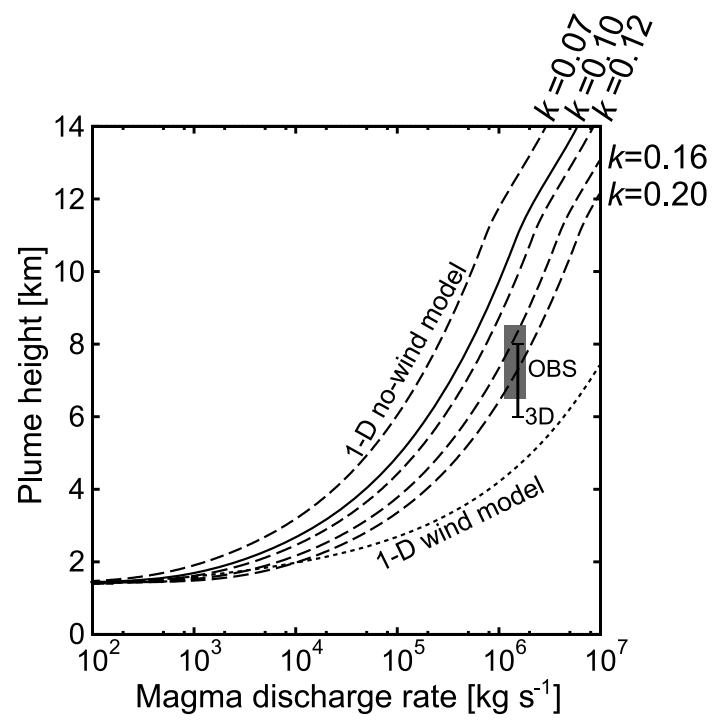

Fig. 6. Plume heights as a function of magma discharge rate for a magma with properties identical to those of the 2011 Shinmoe-dake eruptions. Error bar represents the range of plume heights based on the $3 \mathrm{D}$ simulations using a magma discharge rate of $1.5 \times 10^{6} \mathrm{~kg} \mathrm{~s}^{-1}$, with the shaded zone representing the relationship between plume height and magma discharge rate based on field observations. The curves are the plume heights as a function of magma discharge rate on the basis of the calculations of the 1D no-wind model (Woods, 1988) and the 1D wind model (Bursik, 2001). In these calculations, we assume that the pressure at the vent is equal to atmospheric pressure and the exit velocity is the sound velocity of the mixture. The volatile content, magma temperature, and initial mixture density are given in Table 1 . The solid and dashed curves show the plume heights calculated using the $1 \mathrm{D}$ no-wind model with $k=0.10$ and with $k=0.07,0.12,0.16$, and 0.20 , respectively. The dotted curve is the plume height calculated using the 1D wind model with $\beta=0.7$ (Hewett et al., 1971) and $k=0.1$. of the mechanisms involved in turbulent mixing, primarily because all physical quantities relevant to the mixing process (e.g., velocities for all components, density, and pressure) can be obtained as output data. Figure 7(a) shows the vortical structure of the bent-over plume during the 2011 Shinmoe-dake eruptions, indicating that the plume within the wind field is characterized by a spiral structure of vortices at the plume edge (see also a schematic illustration of Fig. 7(b)), similar to counter-rotating vortices observed in laboratory experiments (Fric and Roshko, 1994). This suggests that this spiral structure creates engulfment flows, leading to an increase in the efficiency of ambient air entrainment by the volcanic plume.

The features observed in Fig. 7(a) cannot be obtained using Eq. (5), which is based on a simple sum of geometrical effects and wind entrainment. Quantitative estimation of effect of the vortical structure shown in Fig. 7(a) on the efficiency of turbulent mixing and plume height needs more systematic 3D model-based analyses, and they are currently in progress. This research will provide a better understanding of mixing processes in volcanic plumes and lead to improved analytical models that allow the rapid assessment of magma discharge rates from plume height (e.g., Degruyter and Bonadonna, 2012).

\section{Concluding Remarks}

We used a 3D numerical model of an eruption cloud to simulate the development of a volcanic plume that was strongly bent over by winds during the 2011 Shinmoe-dake eruptions. These simulation results, such as the height and shape of the plume, agree well with observations based 

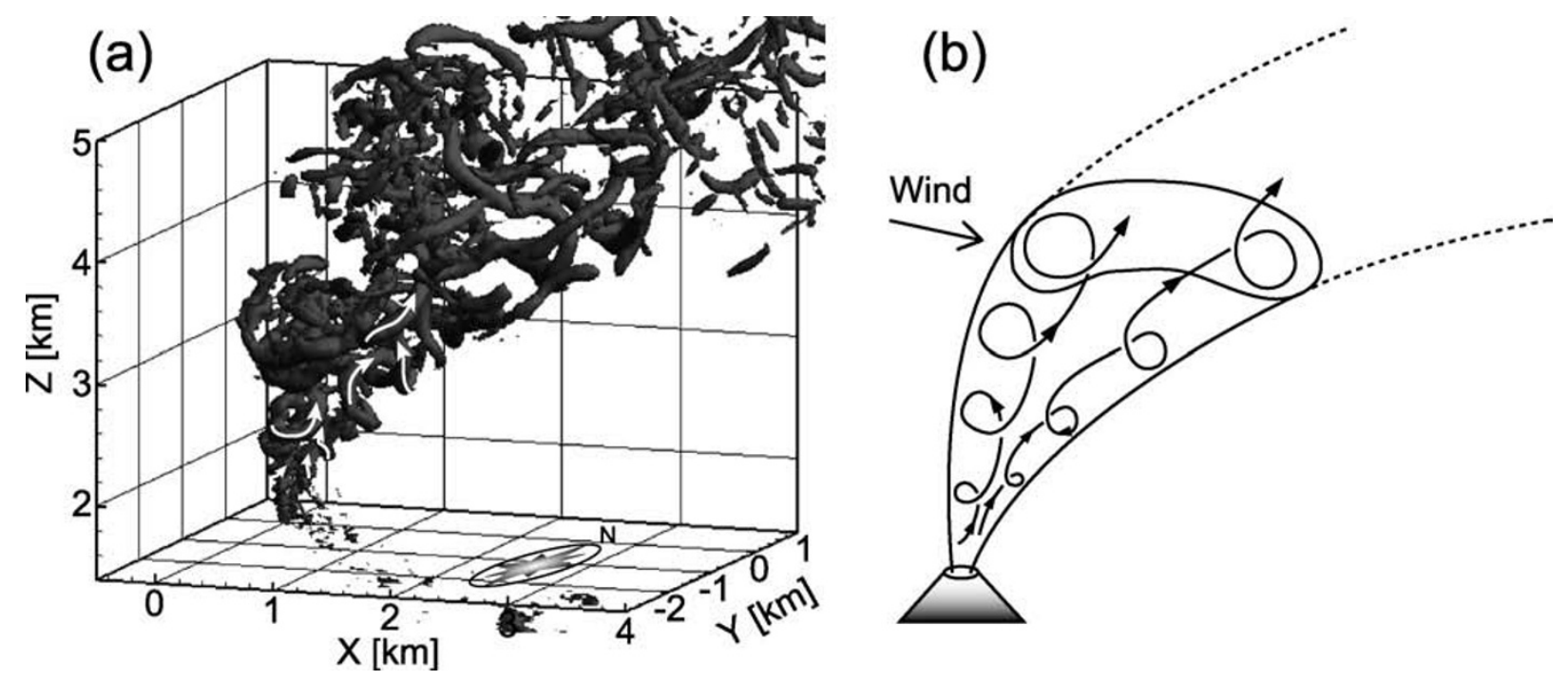

Fig. 7. (a) Vortical structures visualized by a $Q=0.03$ isosurface at $480 \mathrm{~s}$ in the bent-over plume using the results of 3D simulations, where $Q$ represents the local balance between shear strain rate and vorticity magnitude (Chong et al., 1990). Spiral structures are indicated by arrows. Parameters used and vent conditions are given in Table 1. (b) Schematic illustration of vortical structure of a volcanic plume in wind field.

on satellite images and weather radar echo measurements. These plume height simulations indicate that wind substantially enhances the efficiency of turbulent mixing between the eruption cloud and ambient air, leading to a decrease in plume height compared with plumes that form in still environments.

Our results also suggest that the previous 1D wind model overestimates the effects of wind on turbulent mixing efficiency (i.e., the value of $\beta$ ), and hence, underestimates plume height in a strong wind field for a given magma discharge rate. In order to improve the plume height estimations by the $1 \mathrm{D}$ wind model, systematic 3D numerical studies that determine the preferable value of $\beta$ are required.

Our simulation results also clearly indicate that fine ash particles suspended in horizontally moving clouds were transported toward the east-southeast by high-altitude winds, whereas the distribution of fallout from the eruption cloud was strongly controlled by low-altitude winds. This led to the dispersal axis of the main fall deposit extending to the southeast, agreeing well with field observations. However, some of the quantitative features of depositional patterns determined during our simulations are not necessarily consistent with observations during the 2011 Shinmoedake eruptions. For example, minor large clasts with 70$80 \mathrm{~mm}$ in diameter were observed $\sim 7 \mathrm{~km}$ away from the vent, whereas our simulations predict that such large clasts are limited near the vent (within 1-2 km). This inconsistency is considered to result from the assumption in our model that the gas-pyroclasts mixture is ejected at the atmospheric pressure with the sound velocity $\left(134 \mathrm{~m} \mathrm{~s}^{-1}\right)$. On this assumption, the large clasts whose terminal velocities is higher than the above exit velocity necessarily leave from the plume at low level and fall to the ground near the vent. On the other hand, in reality, the eruption intensity fluctuates with time and the exit pressure can be higher than the atmospheric pressure. Under these conditions, the flow just above the vent becomes supersonic and transports large clasts up to higher levels (e.g., Koyaguchi et al., 2010). Fur- ther studies are needed to evaluate the effects of these processes on turbulent mixing and ash dispersal.

Acknowledgments. We acknowledge Akihiro Hashimoto for providing data on atmospheric conditions, and we thank the Earth Simulator Center of the Japan Agency for Marine-Earth Science and Technology, and the Research Institute for Information Technology at Kyushu University for supporting this study. The manuscript was improved by comments from Mie Ichihara, Larry Mastin and an anonymous reviewer. Part of this study was supported by the ERI Cooperative Research Program and the Special Coordination Funds for Promoting Science and Technology from MEXT, "Urgent Study on the 2011 Eruption of KirishimaShinmoe-dake Volcano". The satellite image was provided by Center for Environmental Remote Sensing, Chiba University.

\section{References}

Bonadonna, C., J. C. Phillips, and B. F. Houghton, Modeling tephra sedimentation from a Ruapehu weak plume eruption, J. Geophys. Res., 110, B08209, 2005.

Bursik, M., Effect of wind on the rise height of volcanic plumes, Geophys. Res. Lett., 28(18), 3621-3624, 2001.

Carazzo, G., E. Kaminski, and S. Tait, On the dynamics of volcanic columns: A comparison of field data with a new model of negatively buoyant jets, J. Volcanol. Geotherm. Res., 178, 94-103, 2008.

Chong, M. S., A. E. Perry, and B. J. Cantwell, A general classification of three-dimensional flow fields, Phys. Fluids A, 2, 765-777, 1990.

Degruyter, W. and C. Bonadonna, Improving on mass flow rate estimates of volcanic eruptions, Geophys. Res. Lett., 39, L16308, 2012.

Dimotakis, P. E., The mixing transition in turbulent flows, J. Fluid Mech., 409, 69-98, 2000.

Fric, T. F. and A. Roshko, Vortical structure in the wake of a transverse jet, J. Fluid Mech., 279, 1-47, 1994.

Hashimoto, A., T. Shimbori, and K. Fukui, Tephra fall simulation for the eruptions at Mt. Shinmoe-dake during 26-27 January 2011 with JMANHM, SOLA, 8, 37-40, 2012.

Hewett, T. A., J A. Fay, and D. P. Hoult, Laboratory experiments of smokestack plumes in a stable atmosphere, Atmos. Environ., 5, 769789, 1971.

Koyaguchi, T., Y. J. Suzuki, and T. Kozono, Effects of the crater on eruption column dynamics, J. Geophys. Res., 115, B07205, 2010.

Kozono, T., H. Ueda, T. Ozawa, T. Koyaguchi, E. Fujita, A. Tomiya, and Y. J. Suzuki, Magma discharge variations during the 2011 eruptions of Shinmoe-dake volcano, Japan, revealed by geodetic and satellite observations, Bull. Volcanol., 75:695, 2013.

Kunii, D. and O. Levenspiel, Fluidization Engineering, John Wiley, New 
York, 1969.

Maeno, F., M. Nagai, S. Nakada, R. Burden, S. Engwell, Y. Suzuki, and T. Kaneko, Constraining tephra dispersion and deposition from cyclic subplinian explosions at Shinmoedake volcano, Kyushu, Japan, 2011, Japan Geoscience Union Meet., SVC50-07, 2012.

Morton, B. R., G. I. Taylor, and J. S. Turner, Turbulent gravitational convection from maintained and instantaneous sources, Proc. R. Soc. London, Ser. A, 234(1196), 1-23, 1956.

Ogden, D. E., K. H. Wohletz, G. A. Glatzmaier, and E. E. Brodsky, Numerical simulations of volcanic jets: importance of vent overpressure, $J$. Geophys. Res., 113, B02204, 2008.

Roe, P. L., Approximate Riemann solvers, parameter vectors, and difference schemes, J. Comput. Phys., 43, 357-372, 1981.

Sarna-Wojcicki, A. M., S. Shipley, R. B. Waitt Jr., D. Dzurisin, and S. H. Wood, Areal distribution, thickness, mass, volume, and grain size of air-fall ash from the six major eruptions of 1980, in The 1980 Eruptions of Mount St. Helens, edited by P. W. Lipman and R. L. Christiansen, 577-601, U. S. Geological Survey, 1981.

Shimbori, T. and K. Fukui, Time variation of the eruption cloud echo height from Shinmoe-dake volcano in 2011 observed by Tanegashima and Fukuoka weather radars: Part II, Rep. Coord. Comm. Predict. Volcan. Erup. 109, 2012 (in Japanese) (in Printing).

Sparks, R. S. J., The dimensions and dynamics of volcanic eruption columns, Bull. Volcanol., 48, 3-15, 1986.

Suzuki, Y., A. Yasuda, N. Hokanishi, T. Kaneko, S. Nakada, and T. Fu- jii, Syneruptive deep magma transfer and shallow magma remobilization during the 2011 eruption of Shinmoe-dake, Japan-Constraints from melt inclusions and phase equilibria experiments-, J. Volcanol. Geotherm. Res., 257, 184-204, 2013.

Suzuki, Y. J. and T. Koyaguchi, A three-dimensional numerical simulation of spreading umbrella clouds, J. Geophys. Res., 114, B03209, 2009.

Suzuki, Y. J. and T. Koyaguchi, Numerical determination of the efficiency of entrainment in volcanic eruption columns, Geophys. Res. Lett., 37, L05302, 2010.

Suzuki, Y. J., T. Koyaguchi, M. Ogawa, and I. Hachisu, A numerical study of turbulent mixing in eruption clouds using a three-dimensional fluid dynamics model, J. Geophys. Res., 110, B08201, 2005.

van Leer, B., Towards the ultimate conservative difference scheme III. Upstream-centered finite-difference schemes for ideal compressible flow, J. Comput. Phys., 23, 263-275, 1977.

Wang, H. and A. W.-K. Law, Second-order integral model for a round turbulent buoyant jet, J. Fluid Mech., 459, 397-428, 2002.

Woods, A. W., The fluid dynamics and thermodynamics of eruption columns, Bull. Volcanol., 50, 169-193, 1988.

Woods, A. W. and S. M. Bower, The decompression of volcanic jets in a crater during explosive volcanic eruptions, Earth Planet. Sci. Lett., 131, 189-205, 1995.

Y. J. Suzuki (e-mail: yujiro@eri.u-tokyo.ac.jp) and T. Koyaguchi 